\title{
Calcium coordination compounds of dipicolinic and quinolinic acids: synthesis, characterization, crystal structures and DFT studies
}

Adedibu Clement Tella ( $\sim$ ac_tella@yahoo.co.uk)

University of Ilorin https://orcid.org/0000-0003-2090-4747

Adetola Christianah Oladipo

Landmark University

Victoria Tosin Olayemi

Kwara State University

Allen Gordon

Nelson Mandela University

Adeniyi Sunday Ogunlaja

Nelson Mandela University

Lukman Olawale Alimi

Stellenbosch University

\section{Stephen Argent}

University of Nottingham

\section{Robert Mokaya}

University of Nottingham

\section{Guy Clarkson}

University of Warwick

Richard Walton

University of Warwick

\section{Research Article}

Keywords: Alkali metals, Molecular orbitals, Pyridine carboxylate, Calcium coordination compounds

Posted Date: January 27th, 2022

DOI: https://doi.org/10.21203/rs.3.rs-1251688/v1

License: (c) (1) This work is licensed under a Creative Commons Attribution 4.0 International License.

Read Full License 


\section{Abstract}

In the past two decades various N-heterocyclic carboxylate coordination compounds have been synthesized with intriguing architectures and potential applications as functional materials. In this regard, two novel calcium coordination compounds $\left[\mathrm{Ca}(2,6-\mathrm{Hpdc})_{2}\left(\mathrm{H}_{2} \mathrm{O}\right)_{2}\right] 1$ and $\left[\mathrm{Ca}_{2}(2,3-\mathrm{pdc})_{2}\left(\mathrm{H}_{2} \mathrm{O}\right)_{6}\right]_{n} \mathbf{2}$ (where 2,6- $\mathrm{H}_{2} \mathrm{pdc}=2,6$-pyridinedicarboxylic acid and 2,3- $\mathrm{H}_{2} \mathrm{pdc}=2,3$-pyridinedicarboxylic acid) were grown at room temperature. The compounds were characterized using elemental analysis, Fourier Transform infrared (FT-IR) spectroscopy, thermogravimetric analysis, powder X-ray diffraction and single crystal Xray crystallographic analysis. Compounds 1 and 2 crystallize in orthorhombic space group Pccn and monoclinic space group $P c$, respectively. The structures of both compounds are stabilized by a network of hydrogen bonds arising from coordinated water molecules and carboxylate groups. Computational analysis revealed that compound 1 has a large energy gap $(9.221 \mathrm{eV})$ suggesting high excitation energies and chemical hardness making it a better electron acceptor while compound $\mathbf{2}$ displayed a smaller energy gap $(5.156 \mathrm{eV})$ which is indicative of a softer molecule with better polarizability and reactivity.

\section{Introduction}

In recent years, there has been wide development of coordination compounds, composed of metal centres and organic ligands. Their relevance in many fields like organic and inorganic chemistry, biochemistry, material science, electrochemistry and pharmacology with many potential applications, such as catalysis, magnetism, adsorption, luminescence biology applications etc, have to extensive study of these compounds [1, 2]. Furthermore, the need for cheap and less toxic coordination compounds for biological applications has necessitated the use of alkaline earth metals [3, 4]. Specifically, calcium is useful in biological processes such as carbohydrate metabolism, enzyme activation and nucleic acid complexation as it is an essential constituent in living organisms [5]. Other applications of calcium based compounds include sensing [6], catalysis [7] and adsorption of gases [8].

In the same way, ligands with mixed-functionalities such as pyridinecarboxylate, pyrazinecarboxylate, imidazolecarboxylate have been reported to favours the design of diverse structure of coordination compounds with fascinating potential application [9-11]. Furthermore, these ligands are known to possess strong and weak hydrogen bonding (such as $\mathrm{O}-\mathrm{H} \cdots \mathrm{O}$ and $\mathrm{C}-\mathrm{H} \cdots \mathrm{O}$ ) and $\pi-\pi$ stacking interactions, which influences their biological properties [12-15].

The synthesis of calcium compounds of trimellitate ligand have been reported in the literature [16-19] Calcium coordination polymer was built up from infinite chains of calcium polyhedra interconnected to each other through the trimellitate ligands [16]. Four three-dimensional (3D) calcium-based coordination compounds were constructed from 2,5-dibromoterephthalic acid. The tuning and formation of different network topologies were explored by the introduction of different $\mathrm{N}$-donor organic species as additional auxiliary ligands to the system, the fluorescence properties of the compounds were also reported [17]. In a report, calcium coordination compounds of three different chlorophenoxyacetic acids (3-Chlorophenol, 4chloro-2-methylphenol, 2,4,6-trichlorophenol) were synthesized. Differences in the number and position of 
the chlorine substituents were reported to lead to diversities in the crystal structures of the three calcium compounds obtained. Furthermore, a steric hindrance effect and the formation of $\mathrm{O}-\mathrm{H} \cdots \mathrm{Cl}$ hydrogen-bond contributed to the enrichment of the structures [18]. A Ca(II) coordination compound of L-malic acid was synthesized and reported to have high thermal stability. In addition, the compound is capable of emitting its own characteristic sensitized luminescence [19]. A group of researchers synthesized and compared the structures of $\mathrm{Ca}(\mathrm{II}), \mathrm{Mg}(\mathrm{II})$ and $\mathrm{Ba}$ (II) Coordination Compounds of $1 \mathrm{H}$-tetrazolate-5-acetic acid Ligand. They concluded that the nature of metal ions is pivotal in determining their molecular framework [20].

Despite these existing reports, there are still fewer reports on coordination compounds of alkaline earth metals compared to those of transition metals, this is because their geometries are not predictable as their bonding mode is not governed by ligand field stabilization [21].

Carboxylates of s-block metals have high affinity for oxygen donor e.g water [21]. Many researchers have reported their synthesis is aqueous media, e.g hydrothermal synthesis [22-24]. Herein, we report the synthesis of two calcium coordination compounds $\mathbf{1}$ and $\mathbf{2}$ in aqueous medium alongside suitable solvents, using solvothermal and room temperature synthetic reactions respectively. Furthermore, DFT study was employed to gain insight on the electronic properties of the compounds.

\section{Experimental}

\section{Materials and methods}

All reagents and chemicals were of analytical grade and were used as received without further purification. 2,3-pyridinedicarboxylic acid and 2,6-pyridinedicarboxylic acid were purchased from Sigma Aldrich, Germany. Calcium nitrate tetrahydrate $\left(\mathrm{Ca}\left(\mathrm{NO}_{3}\right)_{2} \cdot 4 \mathrm{H}_{2} \mathrm{O}\right)$ was supplied by Alfa Aesar, UK. Ethanol (98.8\%), N,N-dimethyl formamide (DMF) (99.0\%) were obtained from Central Drug House (P) Ltd, New Delhi, India.

\section{Synthesis of the compounds}

$\mathrm{Ca}(2,6-\mathrm{Hpdc})_{2}\left(\mathrm{H}_{2} \mathrm{O}\right)_{2} 1$

Compound 1 was prepared by dissolving 2,6-pyridinedicarboxylic acid (2,6- $\left.\mathrm{H}_{2} \mathrm{pdc}\right)(0.167 \mathrm{~g}, 1 \mathrm{mmol})$ and $\mathrm{Ca}\left(\mathrm{NO}_{3}\right)_{2} \cdot 4 \mathrm{H}_{2} \mathrm{O}(0.118 \mathrm{~g}, 0.5 \mathrm{mmol})$ in two separate $50 \mathrm{~mL}$ beakers containing $10 \mathrm{~mL}$ ethanol and $10 \mathrm{~mL}$ distilled water, respectively. The solutions were mixed while stirring gently to obtain a clear colourless solution that was heated in an oven at $100^{\circ} \mathrm{C}$ for 4 hours under atmospheric conditions. The resulting clear colourless solution was kept standing undisturbed on the bench. White diamond-shaped crystals were obtained after 27 days. The crystals were separated from the mother liquor by filtration and washed in ethanol-water (2:1 by volume) solution and dried at room temperature for $30 \mathrm{~min}$. Yield: $69 \%$; Melting 
point: $479{ }^{\circ} \mathrm{C} ; \mathrm{C}_{14} \mathrm{H}_{12} \mathrm{~N}_{2} \mathrm{O}_{10} \mathrm{Ca}(408.34 \mathrm{~g} / \mathrm{mol}$ ); Anal. found: $\mathrm{C}, 41.14, \mathrm{H}, 2.76, \mathrm{~N}, 6.76 \%$; Calc: $\mathrm{C}, 41.39, \mathrm{H}$, 2.48, N, 6.89\%.; IR ( $\left.\mathrm{cm}^{-1}\right): 3441,3194,1707,1542,1372,540,424$.

$\left[\mathrm{Ca}_{2}(2,3-\mathrm{pdc})_{2}\left(\mathrm{H}_{2} \mathrm{O}\right)_{6}\right]_{\mathrm{n}} 2$

Compound 2 was prepared by dissolving 2,3-pyridinedicarboxylic acid (2,3-pdc) (0.334 g, $2 \mathrm{mmol})$ and $\mathrm{Ca}\left(\mathrm{NO}_{3}\right)_{2} .4 \mathrm{H}_{2} \mathrm{O}(0.236 \mathrm{~g}, 1 \mathrm{mmol})$ in two separate $50 \mathrm{~mL}$ beakers containing $10 \mathrm{~mL}$ distilled water and $10 \mathrm{~mL}$ DMF, respectively. The solutions were mixed together and stirred for 2 hours at ambient temperature. The resulting clear colourless solution was kept standing undisturbed on the bench. Colourless block-shaped crystals were formed after 22 days, filtered out of the solution and washed in ethanol-water (2:1 by volume) solution and dried at room temperature for $30 \mathrm{~min}$. Yield: 76\%; Melting point: $424^{\circ} \mathrm{C} ; \mathrm{C}_{14} \mathrm{H}_{18} \mathrm{~N}_{2} \mathrm{O}_{14} \mathrm{Ca}_{2}(518.46 \mathrm{~g} / \mathrm{mol})$; Anal. found: $\mathrm{C}, 32.87$ (32.43); $\mathrm{H}, 3.39$ (3.47); N, 5.46\% (5.41); Calc: C,32.43; H, 3.47; N, 5.41\%.; IR; $\left(\mathrm{cm}^{-1}\right)$ : 3412, 2904, 1562, 1454, 1332, 662, 497.

\section{Instrumentation and characterization}

The samples were characterized by elemental analysis using an Exeter Analytical CE-440 Elemental Analyser. The infrared spectra were recorded using a Bruker Alpha diamond module FT-IR spectrometer with attenuated total reflectance (ATR) attachment for solid samples. Powder X-ray diffraction (PXRD) patterns were measured on a PANalytical X'Pert PRO diffractometer with a Cu-Ka source ( $40 \mathrm{kV}, 40 \mathrm{~mA})$ with a step size of $0.02^{\circ}$ and a $50 \mathrm{~s}$ time step. TGA was performed using an SDT-Q600 TA instrument. The samples were heated in air with a heating rate of $10^{\circ} \mathrm{C} \mathrm{min}-1$ and the scan was recorded within the temperature range of $30-800{ }^{\circ} \mathrm{C}$. Single crystal X-ray data for 1 were collected at $120 \mathrm{~K}$ on an Oxford Diffraction GV1000 diffractometer equipped with an Atlas S2 detector and mirror monochromated microfocus Cu source while 2 was collected at $150 \mathrm{~K}$ on Agilent Xcalibur Gemini diffractometer with a Ruby CCD area detector. Olex2 suite was used as a graphic user interface (GUI) and as imaging software [25]. The structures were solved with the ShelXT [26] structure solution program using intrinsic phasing and refined with the ShelXL [27] refinement package using least squares minimisation. All nonhydrogen atoms were refined with anisotropic displacement parameters and images were prepared via Mercury 4.1.0.

\section{Computational Details}

Theoretical studies were performed for 1 and 2. The input files were taken from the CIF obtained from reported X-ray single crystal measurements. The geometries were optimized by minimizing energies with respect to all geometrical parameters without imposing any molecular symmetry constraints. Computational studies were carried out using the Gaussian 09 software package [28]. The calculations were performed by using B3LYP method (standard hybrid density functional method) with a basis set of $6-311++G * \star(2 p, 2 d)$ level [29]. 


\section{Results And Discussion Structural description}

The crystal data and structure refinement parameters of $\mathbf{1}$ and $\mathbf{2}$ are given in Table 1 
Table 1

Crystal data, data collection and structure refinement details for $\mathbf{1}$ and $\mathbf{2}$

\begin{tabular}{|c|c|c|}
\hline Details & 1 & 2 \\
\hline Empirical formula & $\mathrm{C}_{14} \mathrm{H}_{12} \mathrm{CaN}_{2} \mathrm{O}_{10}$ & $\mathrm{C}_{14} \mathrm{H}_{18} \mathrm{Ca}_{2} \mathrm{~N}_{2} \mathrm{O}_{14}$ \\
\hline Formula weight & 631.88 & 518.46 \\
\hline $\mathrm{T}(\mathrm{K})$ & $120(2)$ & $150(2)$ \\
\hline Wavelength $(\AA ̊)$ & 1.54184 & 1.54184 \\
\hline Crystal system & Orthorhombic & monoclinic \\
\hline Space group & Pccn & $P C$ \\
\hline Crystal size $\left(\mathrm{mm}^{3}\right)$ & $0.443 \times 0.202 \times 0.163$ & $0.22 \times 0.16 \times 0.12$ \\
\hline $\mathrm{a}(\AA)$ & $9.8403(9)$ & $13.50490(10)$ \\
\hline$b(\AA)$ & $12.1668(12)$ & $10.27230(10)$ \\
\hline$c(\AA)$ & $12.7110(10)$ & $7.25040(10)$ \\
\hline$a\left(^{0}\right)$ & 90 & 90 \\
\hline$\beta\left(^{\circ}\right)$ & 90 & $104.4030(10)$ \\
\hline$Y\left(^{\circ}\right)$ & 90 & 90 \\
\hline$V\left(\AA^{3}\right)$ & $1521.8(2)$ & $974.209(18)$ \\
\hline Z & 4 & 2 \\
\hline$\rho_{\text {calc }}\left(\mathrm{g} / \mathrm{cm}^{3}\right)$ & 1.379 & 1.767 \\
\hline$\mu / \mathrm{mm}^{1}$ & 2.462 & 5.845 \\
\hline$F\left(\begin{array}{lll}0 & 0 & 0\end{array}\right)$ & 638.0 & 536.0 \\
\hline $\begin{array}{l}2 \Theta \text { range for data } \\
\text { collection }\left(^{(}\right)\end{array}$ & 11.566 to 150.262 & 6.758 to 146.658 \\
\hline Radiation type & $\mathrm{Cu} \mathrm{Ka}$ & $\mathrm{Cu} \mathrm{Ka}$ \\
\hline Index ranges & $\begin{array}{l}-11 \leq h \leq 12,-15 \leq k \leq 14,-10 \leq l \\
\leq 15\end{array}$ & $\begin{array}{l}-16 \leq h \leq 16,-12 \leq k \leq 12,-8 \leq \\
l \leq 8\end{array}$ \\
\hline Data/restraints/parameters & $1515 / 4 / 132$ & $3625 / 9 / 300$ \\
\hline Independent reflections & $\begin{array}{l}1515\left[R_{\text {int }}=0.0308, R_{\text {sigma }}=\right. \\
0.0275]\end{array}$ & $\begin{array}{l}3625\left[R_{\text {int }}=0.0236, R_{\text {sigma }}=\right. \\
0.0185]\end{array}$ \\
\hline
\end{tabular}




\begin{tabular}{|lll|}
\hline Details & $\mathbf{1}$ & $\mathbf{2}$ \\
\hline Goodness-of-fit on $\mathrm{F}^{2}$ & 1.066 & 1.082 \\
\hline Reflections collected & 3446 & 18534 \\
$\mathrm{R}_{1}[$ l>2 $\sigma(\mathrm{I})]$ & 0.0559 & 0.0172 \\
\hline${ }{ }{ }_{2}$ (all data) & 0.1578 & 0.0465 \\
\hline Largest peak $\left(\mathrm{e} \mathrm{A}^{3}\right)$ & 0.92 & 0.17 \\
\hline Deepest hole $\left(\mathrm{e} \mathrm{A}^{3}\right)$ & -0.77 & -0.18 \\
\hline
\end{tabular}

Compound 1 crystallized in the orthorhombic space group Pccn. The asymmetric unit comprises of one crystallographically independent $\mathrm{Ca}$ (II) ion, one 2,6- $\mathrm{H}_{2} \mathrm{pdc}$ anion and a coordinated water molecule. The $\mathrm{Ca}$ (II) center coordinates to two oxygen atoms (08) from two 2,6- $\mathrm{H}_{2}$ pdc ligands, two oxygen atoms (011) from two half deprotonated carboxylate groups, two oxygen atoms (013) from two coordinated water molecules and two nitrogen atoms (N1) from two 2,6- $\mathrm{H}_{2}$ pdc ligands resulting in a distorted dodecahedral geometry (Fig. 1a). Selected bond lengths and angles are given in Table S1. The Ca- $\mathrm{O}_{\text {carb }}$ distances are in the range 2.4446(15) $\AA$ - 2.6891(17) $\AA$ and Ca-N is 2.5612 $\mathrm{A}$ which are similar to those observed in reported calcium coordination compounds [17]. The $\mathrm{Ca}-\mathrm{O}_{\text {water }}$ bond length is $2.3177(16) \AA$. The $\mathrm{O}-\mathrm{Ca}-\mathrm{O}$ bond angles for $\mathrm{Ca} 1$ ranges from $58.40(5)^{\circ}$ to $173.79(8)^{\circ}$ (Table 1b). The carboxylate group angles 08C7-09 and $011-\mathrm{C} 10-012$ are $126.26(19)^{\circ}$ and $125.32^{\circ}$ respectively, which is slightly wider than the $\mathrm{O}=\mathrm{C}-\mathrm{O}$ angle of pure dipicolinic acid $\left(123.81(9)^{\circ}\right)$ [30], possibly due to distortion by metal ion coordination. Furthermore, the torsional angle between the carboxylate group and the pyridyl ring (C3-C2-C7-08) is $173.0(3)^{\circ}$ and it is indicative of anti-coplanar conformation [31].

Interestingly, the $011-\mathrm{H} 11$ group of the half deprotonated carboxylic group forms a strong intermolecular hydrogen bond with adjacent carboxylate group $(011-\mathrm{H} 11 \cdot \cdots 08=2.5732 \AA)$. The coordinated water also forms a network of intermolecular hydrogen bonds and acts as the hydrogen bond donor (013-

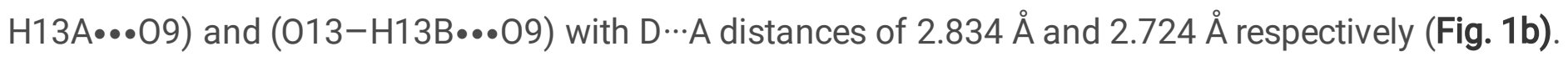
The selected hydrogen bonding parameters for $\mathbf{1}$ are shown in Table S2. The crystal packing shows that the molecules are connected by hydrogen bonds from coordinated water molecules which help in stabilizing the structure (Fig. 1b). The entire framework is further stabilized by $\pi \cdots \pi$ stacking between the centroid of one pyridyl ring (i1) and the centroid of the adjacent pyridyl ring (i2) within a layer (Fig. 1C and Table S3).

Compound 2 belongs to the monoclinic system with space group $P c$, with a dimeric formula $\left[\mathrm{Ca}_{2}(2,3-\right.$ pdc) $\left.{ }_{2}\left(\mathrm{H}_{2} \mathrm{O}\right)_{6}\right]_{n}$. It has two coordination centers [Ca1 and Ca2], inducing a complete deprotonation of $\mathrm{H}_{2}$ pdc, which in turn affects the structural functionalities of the carboxylic residues. The asymmetric unit comprises of two $\mathrm{Ca}$ (II) ions, two 2,3- $\mathrm{H}_{2}$ pdc anions and six coordinated water molecules (Fig. 2). The coordination number of $\mathrm{Ca} 1$ in 2 is seven, the polyhedron being pentagonal bipyramid formed by one $\mathrm{N}, \mathrm{O}$ 
set from one 2,3- $\mathrm{H}_{2}$ pdc molecule, two oxygen atoms from two 2,3-pdc molecules and three oxygen atoms of three water molecules, one of which bridges $\mathrm{Ca} 1$ and $\mathrm{Ca} 2$. The coordination number of $\mathrm{Ca} 2$ is also seven (one $\mathrm{N}, \mathrm{O}$ set from one 2,3- $\mathrm{H}_{2}$ pdc molecule, one oxygen atom from one 2,3- $\mathrm{H}_{2}$ pdc molecule, and four oxygen atoms of four water molecules (including the bridging water molecule) and exhibits pentagonal bipyramid geometry (Fig. 3) The angle Ca1-01-Ca2 is $130.05^{\circ}$, which results in the $\mathrm{Ca} 1-\mathrm{Ca} 2$ distance of $4.5741 \AA$. The $\mathrm{O}-\mathrm{Ca}-\mathrm{O}$ bond angles for $\mathrm{Ca} 1$ and $\mathrm{Ca} 2$ ranges from $68.99(5)^{\circ}$ to $149.00(5)^{\circ}$ while the $\mathrm{O}-\mathrm{Ca}-\mathrm{N}$ bond angles are $130.25(6)^{\circ}$ similar to what was obtained for some calcium compounds of nitrogen-containing ligands. [20] Distances were found to be $2.6142 \AA$ (Ca-N), 2.3725- 2.4044 $\AA$ [CaOcarb] and 2.3706-2.5049 $\AA$ [Ca-O $\left(\mathrm{H}_{2} \mathrm{O}\right)$ ]. The [Ca-Ocarb] distances are similar to those observed in calcium carboxylate coordination compounds.[17] Selected bond lengths have been listed in Table S1.

There are two modes of coordination of the $2,3-\mathrm{H}_{2}$ pdc residue. In the first mode around $\mathrm{Ca} 1$, one of the carboxylate groups (0101) coordinates monodentately and bridges $\mathrm{Ca} 1 \mathrm{atom}$, while the other carboxylate group coordinates bidentately, with one of the oxygen atoms (0110) bridging a Ca1 atom and the other (0109) chelating another Ca1 atom with the pyridine nitrogen (N107). In the second mode around Ca2, both carboxylate groups coordinate monodentately, with the coordinating oxygen of one group (0201) bridging a Ca2 atom and the coordinating oxygen of the other group (0210) chelating another $\mathrm{Ca} 2$ atom with the pyridine nitrogen (N207). These features were observed in heteronuclear compounds of $\mathrm{H}_{2} \mathrm{pdc}$ [9].

The distance between $\mathrm{Ca}$ atom and the chelating oxygen atom (0109) is slightly longer than that of the bridging oxygen atom (0110), indicating the stronger bond of the latter. The plane of the carboxylic group of 2,3- $\mathrm{H}_{2}$ pdc ligand (C204-C203-C202-0201) is anti-coplanar with that of the aromatic ring, with a torsional angle of $103.08^{\circ}$. Apart from these interatomic distances between the centre metal and other heteroatoms, the crystal packing of compound 2 reveals there are $\mathrm{O}-\mathrm{H} \cdots \mathrm{O}$ hydrogen bonding interactions between the coordinated water molecules and the carboxylate of the 2,3- $\mathrm{H}_{2}$ pdc molecules with donoracceptor ( $\mathrm{D} \cdots \mathrm{A})$ distance in the range of 1.990-2.911 $\AA$ (Fig. 4 and Table S4). In addition to the $\mathrm{O}-\mathrm{H} \cdots \mathrm{O}$ interactions, there exists $\mathrm{C}-\mathrm{H} \cdots \mathrm{O}$ intermolecular interactions when viewed along the crystallographic $c$ axis. These interactions connect two adjacent $2,3-\mathrm{H}_{2}$ pdc molecules involving the hydrogen atom from one 2,3- $\mathrm{H}_{2}$ pdc ring and oxygen atom of the carboxylate of the neighbouring $2,3-\mathrm{H}_{2}$ pdc molecule (Fig. 5). The $D$ ‥A distance is $3.458 \AA$.

Compound 2 possesses a 3D framework due to an extended system of hydrogen bonds involving carboxylates and coordinated water molecules as well as the perpendicular $\pi \cdots \cdots$ interactions between the 2,3-pdc layers (Fig. 6 and Table S5). The 3D framework is shown in Fig. 7.

\section{FTIR Studies}

The comparison of the FTIR spectra of the free ligands and compounds $\mathbf{1}$ and $\mathbf{2}$ are shown in Fig. $\mathbf{S} 1$ and S2. For 1 , the characteristic $\mathrm{v}(\mathrm{C}=0)$ and $\mathrm{v}(\mathrm{C}-0)$ absorption band of the parent ligand were observed at 1583 and $1305 \mathrm{~cm}^{-1}$. The absorption bands are shifted to higher and lower frequencies in the spectrum 
of $1,1707 \mathrm{~cm}^{-1}$ and $1291 \mathrm{~cm}^{-1}$ for $\mathrm{v}(\mathrm{C}=0)$ and $\mathrm{v}(\mathrm{C}-\mathrm{O})$ respectively indicating chelation of $\mathrm{Ca}$ (II) ion to the ligand. The asymmetric and symmetric vibrational bands are observed at 1543 and $1372 \mathrm{~cm}^{-1}$. The calculated value $\Delta \mathrm{v}\left(\mathrm{COO}^{-}\right)$is $171 \mathrm{~cm}^{-1}$, confirming a multidentate coordination mode of the $2,6-\mathrm{H}_{2} \mathrm{pdc}$ ligand. However, the $\mathrm{v}(\mathrm{C}-\mathrm{N})$ found in the ligand at $1130 \mathrm{~cm}^{-1}$ is shifted to $1146 \mathrm{~cm}^{-1}$ in the spectrum of 1 due to coordination to the metal [32]. The broad band at $2571 \mathrm{~cm}^{-1}$ is assigned to $0-\mathrm{H}$ of carboxylic acid and is as a result of partial deprotonation of the ligand. The $\mathrm{v}(\mathrm{O}-\mathrm{H})$ for water is observed as a broad band at $3441 \mathrm{~cm}^{-1}$.

The FT-IR spectrum of $\mathbf{2}$ shows significant changes in absorption frequencies that occur at coordination sites, notably is the $-\mathrm{OH}$ band which appears around $3100 \mathrm{~cm}^{-1}$ in the spectrum of $2,3-\mathrm{H}_{2}$ pdc but disappeared in that of compound $\mathbf{2}$ due to the coordination of the deprotonated -OH group to Ca (II) metal. The IR spectra shows useful information related to the carboxylate bands from the metal coordination compounds. 2,3- $\mathrm{H}_{2}$ pdc exhibits the typical $\mathrm{v}(\mathrm{C}=0)$ stretching mode in the $1700-1730 \mathrm{~cm}^{-1}$ range [33] absent in the spectrum of 2 , with new bands appearing at $1650 \mathrm{~cm}^{-1}$ and $1332 \mathrm{~cm}^{-1}$ for the

$\mathrm{v}_{\text {asymmetric }}\left(\mathrm{COO}^{-}\right)$and $\mathrm{v}_{\text {symmetric }}\left(\mathrm{COO}^{-}\right)$respectively, validating the monodentate coordination of the carboxylate group. The vibrational frequency at $1580 \mathrm{~cm}^{-1}$ is ascribed to $\mathrm{v}(\mathrm{C}=\mathrm{N})$. This is shifted in the spectrum to $1562 \mathrm{~cm}^{-1}$ in compound 2 . The presence of coordinated water molecules is shown in the appearance of a new broad characteristic peak of $\mathrm{O}-\mathrm{H}$ of water molecules around $3400 \mathrm{~cm}^{-1}$. New bands observed at $497 \mathrm{~cm}^{-1}$ and $662 \mathrm{~cm}^{-1}$ are those of Ca-O and Ca-N respectively. The bands of $\mathrm{v}(\mathrm{C}-\mathrm{H})$ vibration modes also appear in this range $3087 \mathrm{~cm}^{-1}-2904 \mathrm{~cm}^{-1}$ and partially overlap with the bands of water molecules.

\section{PXRD analysis}

The powder X-ray diffraction (PXRD) data of compounds 1 and $\mathbf{2}$ were collected to ascertain their phase purity. The PXRD patterns of the as-synthesized samples were plotted against the simulated patterns as shown in Fig. S3 and S4. There was excellent agreement between the simulated and the experimental patterns which indicates high bulk purity of the as-synthesized phases.

\section{Thermal Analysis}

The TGA curves of compounds 1 and 2 are presented in Fig. 8. TGA curve of 1 shows a mass loss between $213^{\circ} \mathrm{C}$ to $292^{\circ} \mathrm{C}$ (56.10\% found (calc. $\left.50.49 \%\right)$ ) assigned to the loss of two water molecules and a molecule of $2,6-\mathrm{H}_{2}$ pdc ligand. The large difference between the experimental and calculated values may suggest the presence of excess surface water. A steady mass loss was further observed up to $474^{\circ} \mathrm{C}$ (22.90\% found (calc. $19.55 \%)$ ) after which the framework collapsed leaving behind a residue of $\mathrm{CaO}$. Compound 2 shows three thermal mass loss stages. The six molecules of water are lost in the first step, and this amounts to $21 \%(20.8 \%)$ of the total weight. The two $2,3-\mathrm{H}_{2}$ pdc residues of weight $54 \%$ were lost in two indistinct steps, first between $400-530^{\circ} \mathrm{C}$ and the second between $530-725^{\circ} \mathrm{C}$. CaO residue was left till $800^{\circ} \mathrm{C}$. The melting points were found to range between $248-250^{\circ} \mathrm{C}$ and $186-188^{\circ} \mathrm{C}$ for $2,6-\mathrm{H}_{2} \mathrm{pdc}$ and 
2,3- $\mathrm{H}_{2} \mathrm{pdc}$ ligands respectively. The results of the thermal analysis show that the compounds are more thermally stable than some metal coordination compounds of pyridinedicarboxylate $[9,12]$. However, the thermal stability of beyond $400{ }^{\circ} \mathrm{C}$ was reported for some calcium coordination compounds [19, 34].

\section{DFT Studies}

\section{Optimized Molecular Structure}

The full geometry of $\mathbf{1}$ and $\mathbf{2}$ in Pccn and Pn symmetry was optimized (Fig. S5a \& S5b), and the optimized crystal structures were very similar to those obtained by $\mathrm{X}$-ray diffraction. The calculated bond parameters are presented in Table S2. 1 presents an underestimation of $\mathrm{Ca}-\mathrm{O}\left(\mathrm{H}_{2} \mathrm{O}\right)$ bond lengths $(\sim 2.424$ $\AA)$ compared to $2(\sim 2.543 \AA)$ and this is due to the varying electron donation groups influenced by intramolecular interaction (H-bonding) within 2.

\section{HOMO-LUMO energy gap}

The HOMO-LUMO gap describes the stability of molecules, and it predicts reactivity between species by providing the electrical transport properties as well as electron carrier and mobility in molecules [35-37]. The calculated HOMO and LUMO energies of 1 and $\mathbf{2}$ are summarized in Table 3. As shown in Fig. 9, the charge density distribution of 1 illustrates that the HOMO density is mainly located around the 2,6pyridinedicarboxylic acid $\left(2,6-\mathrm{H}_{2} \mathrm{pdc}\right)$ ligand, especially their nitrogen atom/imine and caboxylic groups, there are some indication that calcium atom may partly contribute to HOMO (Fig. 9). The LUMO density is localized on around the 2,6-pyridinedicarboxylic acid $\left(2,6-\mathrm{H}_{2} \mathrm{pdc}\right)$ ligand. With $\mathbf{2}$, the HOMO density is mainly located around the 2,6-pyridinedicarboxylic acid (2,6- $\left.\mathrm{H}_{2} \mathrm{pdc}\right)$ ligand and the LUMO density is centred on the 2,6-pyridinedicarboxylic acid (2,6- $\mathrm{H}_{2} \mathrm{pdc}$ ) ligand (around nitrogen and oxygen atoms) and the calcium atom (Fig. 10). Compound 2 displayed the smallest energy gap (5.156 eV) which is indicative of the softest molecule with better polarizability. Similarly, the lowest LUMO energy $\left(\mathrm{E}_{\mathrm{LUMO}}=1.874 \mathrm{eV}\right)$, which means that it can be the best acceptor of electrons [38]. 1 is characterized with an energy gap $\left(\Delta \mathrm{E}_{\text {gap }}=9.221 \mathrm{eV}\right)$ and this may indicate a molecule with high excitation energy, good stability and a high chemical hardness (Table 2). The HOMO-LUMO orbitals in $\mathbf{1}$ and $\mathbf{2}$ are presented in Fig. 9 and $\mathbf{1 0}$, respectively.

The ionization potential $(I)$, electron affinity $(A)$, chemical potential $(\mu)$, electronegativity $(\chi)$, global hardness ( $\eta)$, global softness (S) and global electrophilicity $(\omega)$ values were calculated using the HOMO and LUMO energy values [39]. The HOMO energy ( $\left.\mathrm{E}_{\mathrm{HOMO}}\right)$ is related to ionization potential $(I)$ by Koopman's theorem and LUMO energy ( $\left.E_{\text {LUMO }}\right)$ is related to electron affinity $(A)[40]$ by the following relations:

Ionization potential $(I)=-E_{\mathrm{HOMO}}$

Electron affinity $(A)=-E_{\text {LUMO }}$ 
Absolute electronegativity $(X)$ is related to average value of HOMO and LUMO energies defined by Mulliken [41].

Electronegativity $x=\frac{I+A}{2}$

The softness $(S)$ is reciprocal of the hardness ( $\eta$ ) [42]

Global hardness, $\square=\frac{I-A}{2}$

Global softness, $S=\frac{1}{\square}$

Parr et al. defined global electrophilicity index ( $\omega)$ [43]

Electrophilicity index $\omega=\frac{\mu^{2}}{2 \square}$

where $\mu$ is the chemical potential takes the average value of ionization potential $(I)$ and electron affinity (A) [44].

Chemical potential $\mu=-\left(\frac{I+A}{2}\right)$ 
Table 2

Quantum chemical descriptors of

1 and 2

\begin{tabular}{|lll|}
\hline Parameter & $\mathbf{1}$ & $\mathbf{2}$ \\
\hline $\mathrm{E}_{\text {HOMO }}(\mathrm{eV})$ & -7.213 & -3.282 \\
$\mathrm{E}_{\mathrm{LUMO}}(\mathrm{eV})$ & 2.008 & 1.874 \\
$\Delta \mathrm{E}_{\text {gap }}(\mathrm{eV})$ & 9.221 & 5.156 \\
$I(\mathrm{eV})$ & 7.213 & 3.282 \\
$\mathrm{~A}(\mathrm{eV})$ & -2.008 & -1.874 \\
$\mu(\mathrm{eV})$ & -2.603 & -0.704 \\
$\chi(\mathrm{eV})$ & 2.603 & 0.704 \\
$\otimes(\mathrm{eV})$ & 4.611 & 2.578 \\
$S(\mathrm{eV})$ & 0.217 & 0.388 \\
$\omega(\mathrm{eV})$ & 0.734 & 0.096 \\
\hline
\end{tabular}

The lowest value of the potential ionization $(I=3.282 \mathrm{eV})$ for $\mathbf{2}$ confirm that it is the better electron donor [45]. Chemical hardness and softness value of $1(\eta=4.611 \mathrm{eV}, S=0.217 \mathrm{eV})$ is greater (lesser) than that of 2 , respectively. Thus, it shows a molecule which is less reactive nature. 1 possesses higher electronegativity value $(X=2.603 \mathrm{eV})$ than 2 , hence making it a better electron acceptor. The value of $\omega$ for $1(\omega=0.734 \mathrm{eV})$ indicates that it is the stronger electrophiles.

\section{Conclusions}

Two calcium coordination compounds of dipicolinate and quinolinate ligands were successfully synthesized. Structural characterization revealed that the $\mathrm{Ca}$ (II) ion in 1 interacts with adjacent carboxylate groups via strong intermolecular hydrogen bonds. On the other hand, 2 revealed two calcium centers, $\mathrm{Ca} 1$ and $\mathrm{Ca} 2$. For the two compounds, the torsional angles between the carboxylate group and the aromatic ring showed that they exhibit anti-coplanar conformation. Optimized molecular structures by DFT simulations are comparable to the crystal structure geometry obtained by X-ray diffraction. Further, theoretical calculations of the HOMO-LUMO energies confirmed that compound $\mathbf{1}$ is a better electron acceptor with less reactivity while compound $\mathbf{2}$ with smaller energy gap is more reactive.

\section{Declarations}

\section{Funding}


The authors appreciate the Royal Society of Chemistry for funding. The School of Chemistry, University of Nottingham and the University of Warwick's Research Technology Platforms, for the provision of facilities for the analysis of the compounds. We are grateful to the Center for High Performance Computing (CHPC), Capetown, South Africa for providing the platform to carry out molecular modelling studies using the Gaussian09 software.

\section{Conflict of Interest}

There are no conflicts to declare.

\section{Availability of data and material}

CCDC 1999478 and CCDC 1954758 contains the crystallographic data of $\mathrm{Ca}(\mathrm{H}(2,6-$ pyr) $)_{2}\left(\mathrm{H}_{2} \mathrm{O}\right)_{2} 1$ and $\left[\mathrm{Ca}_{2}(2,3-\mathrm{pyr})_{2}\left(\mathrm{H}_{2} \mathrm{O}\right)_{6}\right]_{n} 2$ respectively. These data can be obtained free of charge from the Cambridge Crystallographic Data Centre via www.ccdc.cam.ac.uk/structures,

\section{Code availability}

The datasets and codes for DFT modelling generated during the current study will be made available upon request.

\section{Contribution}

Adedibu Clement Tella: Conceptualization, Supervision, Writing- Review, Editing and design of study. Adetola Christianah Oladipo: Data curation, Formal Analysis, Methodology, Writing- Original draft. Victoria Tosin Olayemi: Data curation, Formal Analysis, Methodology, Writing- Original draft. Allen Gordon: DFT modelling, Writing- Review, Editing and design of study.

Adeniyi Sunday Ogunlaja: DFT modelling, Supervision, Writing- Review, Editing and design of study.

Lukman Olawale Alimi: Conceptualization, Supervision, Writing- Review, Editing and design of study.

Stephen Argent: Single Crystal analyses and Interpretation, Supervision, Writing- review and editing Robert Mokaya: Conceptualization, Supervision, Writing- review, editing and design of study. Guy Clarkson: Single Crystal analyses and Interpretation, Supervision, Writing- review and editing.

Richard Walton: Conceptualization, Supervision, Writing- review, editing and design of study. 


\section{References}

1. Chandrasekhar V, Nagendran S, Baskar V (2002) Organotin assemblies containing Sn-O bonds. Coord Chem Rev 235:1-52 . https://doi.org/10.1016/S0010-8545(02)00178-9

2. Li CP, Du M (2011) Role of solvents in coordination supramolecular systems. Chem Commun 47:5958-5972 . https://doi.org/10.1039/c1cc10935a

3. Han L, Qin L, Xu L, Zhou Y, Sun J, Zou X (2013) A novel photochromic calcium-based metal-organic framework derived from a naphthalene diimide chromophore. Chem Commun 49:406-408 . https://doi.org/10.1039/c2cc37497h

4. Noro SI, Mizutani J, Hijikata Y, Matsuda R, Sato H, Kitagawa S, Sugimoto K, Inubushi Y, Kubo K, Nakamura T (2015) Porous coordination polymers with ubiquitous and biocompatible metals and a neutral bridging ligand. Nat Commun 6:1-9 . https://doi.org/10.1038/ncomms6851

5. Fromm KM (2008) Coordination polymer networks with s-block metal ions. Coord Chem Rev 252:856-885 . https://doi.org/10.1016/j.ccr.2007.10.032

6. Bar-Shir A, Gilad AA, Chan KW, Liu G, van Zijl PC, Bulte JW, McMahon MT (2013) Metal ion sensing using ion chemical exchange saturation transfer 19F magnetic resonance imaging. J Am Chem Soc $135: 12164$

7. Begouin JM, Niggemann M (2013) Calcium-Based Lewis Acid Catalysts. Chem Eur J 19:8030

8. Yeh CT, Lin WC, Lo SH, Kao CC, Lin CH, Yang CC (2012) Microwave synthesis and gas sorption of calcium and strontium metal-organic frameworks with high thermal stability. Cryst Eng Comm 14:1219

9. Lazarescu A, Shova S, Bartolome J, Alonso P, Arauzo A, Balu AM, Simonov YA, Gdaniec M, Turta C, Filoti G, Luque R (2011) Heteronuclear (Co-Ca, Co-Ba) 2,3-pyridinedicarboxylate coordination compounds: Synthesis, structure and physico-chemical properties. Dalt Trans 40:463-471 . https://doi.org/10.1039/c0dt00858c

10. An CX, Lu YC, Shang ZF, Zhang ZH (2008) Syntheses and crystal structures of the metal coordination compounds based on pyrazolecarboxylic acid ligands. Inorg Chim Acta 361:2721

11. Ghosh A, Rao KP, Sanguramath RA, Rao CNR (2009) Two-and three-dimensional lead-1H-imidazole4, 5-dicarboxylates. J Mol Struct 927:37

12. Abdolmaleki S, Ghadermazi M, Ashengroph M, Saffari A, Sabzkohi SM (2018) Cobalt (II), zirconium(IV), calcium(II) coordination compounds with dipicolinic acid and imidazole derivatives: X-ray studies, thermal analyses, evaluation as in vitro antibacterial and cytotoxic agents. Inorganica Chim Acta 480:70-82 . https://doi.org/10.1016/j.ica.2018.04.047 
13. Wang N, Yue S, Wu H, Li Z, Li X, Liu Y (2010) Hydrothermal synthesis, crystal structure and magnetic characterization of two 4f-3d heterometallic coordination polymers. Inorganica Chim Acta 363:1008-1012 . https://doi.org/10.1016/j.ica.2009.12.022

14. Kitagawa S, Kitaura R, Noro SI (2004) Functional porous coordination polymers. Angew Chemie Int Ed 43:2334-2375 . https://doi.org/10.1002/anie.200300610

15. Yuoh ACB, Agwara MO, Yufanyi DM, Conde MA, Jagan R, Oben Eyong K (2015) Synthesis, Crystal Structure, and Antimicrobial Properties of a Novel 1-D Cobalt Coordination Polymer with Dicyanamide and 2-Aminopyridine. Int J Inorg Chem 2015:1-8 . https://doi.org/10.1155/2015/106838

16. Volkringer C, Loiseau T, Férey G, Warren JE, Wragg DS, Morris RE (2007) A new calcium trimellitate coordination polymer with a chain-like structure. Solid State Sci 9:455-458 . https://doi.org/10.1016/j.solidstatesciences.2007.04.002

17. Sun $Y$, Sun $Y$, Zheng $H$, Wang $H$, Han $Y$, Yang $Y$, Wang $L$ (2016) Four calcium(II) coordination polymers based on 2,5-dibromoterephthalic acid and different N-donor organic species: Syntheses, structures, topologies, and luminescence properties. CrystEngComm 18:8664-8671 . https://doi.org/10.1039/c6ce01709f

18. Xu X, Yan S, Hu F, Zhao W, Shuai Q (2016) Calcium coordination compounds based on phenoxyacetic acids: Microwave synthesis, thermostability and influences on the crystal structures of chlorine substituent group on ligands. J Coord Chem 69:541-550 . https://doi.org/10.1080/00958972.2015.1126259

19. Raja DS, Luo JH, Chang TG, Lo SH, Wu CY, Lin CH (2013) Synthesis, crystal structure, and luminescence properties of a new calcium(II) coordination polymer based on L-malic acid. J Chem 41:980243 . https://doi.org/10.1155/2013/980243

20. Li QY, Yang GW, Shen L, He MH, Shen W, Gu K, Jin JN (2012) Magnesium(II), calcium(II), and barium(II) coordination compounds constructed by $1 \mathrm{~h}$-tetrazolate-5-acetic acid ligand. Zeitschrift fur Anorg und Allg Chemie 638:826-831 . https://doi.org/10.1002/zaac.201100514

21. Srinivasan BR, Shetgaonkar SY, Ghosh NN (2011) Synthesis and characterization of calcium(II) coordination polymers based on phenylacetic acid. J Coord Chem 64:1113-1124 . https://doi.org/10.1080/00958972.2011.562289

22. Appelhans LN, Kosa M, Radha AV, Simoncic P, Navrotsky A, Parrinello M, Cheetham AK (2009) Phase selection and energetics in chiral alkaline earth tartrates and their racemic and meso analogues: synthetic, structural, computational and calorimetric studies. J Am Chem Soc 131:15375

23. Dietzel PC, Blom R, Fjellvag H (2009) Coordination Polymers Based on the 2,5Dihydroxyterephthalate lon and Alkaline Earth Metal (Ca, Sr) and Manganese Cations. Z Anorg Allg 
24. Tran DT, Chu D, Oliver AJ, Oliver SRJ (2009) Synthesis and characterization of strontium 1,3,5benzenetricarboxylate, [Sr3(1,3,5-BTC)2(H2O)4]·H2O. Inorg Chem Commum 12:351

25. Dolomanov O V., Bourhis LJ, Gildea RJ, Howard JAK, Puschmann H (2009) OLEX2: A complete structure solution, refinement and analysis program. J Appl Crystallogr 42:339-341 . https://doi.org/10.1107/S0021889808042726

26. Sheldrick GM (2015) SHELXT - Integrated space-group and crystal-structure determination. Acta Crystallogr Sect A Struct Chem A71:3-8

27. Sheldrick GM (2015) Crystal structure refinement with SHELXL. Acta Crystallogr Sect C Struct Chem 71:3-8 . https://doi.org/10.1107/S2053229614024218

28. Frisch MJ, Trucks GW, Schlegel HE, Scuseria GE, Robb MA, Cheeseman JR, Scalmani G, Barone V, Petersson GA, O. F, Foresman JB, Fox JD (2016) Gaussian 16. Gaussian, Inc., Wallingford CT

29. Becke AD (1993) Density-functional thermochemistry. III. The role of exact exchange. J Chem Phys 98:5648-5652 . https://doi.org/10.1063/1.464913

30. Téllez VC, Gaytán BS, Bernès S, Vergara EG (2002) The supramolecular structure of pyridine-2,6dicarboxylic acid. Acta Crystallogr Sect C Cryst Struct Commun 58:o228-0230 . https://doi.org/10.1107/S0108270102002172

31. Tripuramallu BK, Manna P, Reddy SN, Das SK (2012) Factors affecting the conformational modulation of flexible ligands in the self-Assembly process of coordination polymers: Synthesis, structural characterization, magnetic properties, and theoretical studies ... Cryst Growth Des 12:777-792 . https://doi.org/10.1021/cg201111r

32. Scaldini FM, Correa CC, Yoshida MI, Krambrock K, Machado FC (2014) 2-D coordination polymers of copper and cobalt with 3,4-pyridinedicarboxylic acid: Synthesis, characterization, and crystal structures. J Coord Chem 67:2967-2982 . https://doi.org/10.1080/00958972.2014.959002

33. Tobias RS (1979) Infrared and Raman Spectra of Inorganic and Coordination Compounds (Nakamoto, Kazuo), fifth. Wiley-Interscience, New York

34. Al-Terkawi AA, Scholz G, Prinz C, Zimathies A, Emmerling F, Kemnitz E (2018) Hydrated and dehydrated $\mathrm{Ca}$-coordination polymers based on benzene-dicarboxylates: Mechanochemical synthesis, structure refinement, and spectroscopic characterization. CrystEngComm 20:946-961 . https://doi.org/10.1039/c7ce01906h

35. Ogunlaja AS, Hosten E, Tshentu ZR (2014) Dispersion of asphaltenes in petroleum with ionic liquids: Evaluation of molecular interactions in the binary mixture. Ind Eng Chem Res 53:18390-18401 . 
36. Olalekan TE, Ogunlaja AS, VanBrecht B, Watkins GM (2016) Spectroscopic, structural and theoretical studies of copper(II) coordination compounds of tridentate NOS Schiff bases. J Mol Struct 1122:72-79 . https://doi.org/10.1016/j.molstruc.2016.05.098

37. Rathi PC, Ludlow RF, Verdonk ML (2020) Practical high-quality electrostatic potential surfaces for drug discovery using a graph-convolutional deep neural network. J Med Chem 63:8778-8790 . https://doi.org/10.1021/acs.jmedchem.9b01129

38. Tella AC, Olayemi VT, Adekola FA, Oladipo AC, Adimula VO, Ogar JO, Hosten EC, Ogunlaja AS, Argent SP, Mokaya R (2021) Synthesis, characterization and density functional theory of copper(II) complex and cobalt(II) coordination polymer for detection of nitroaromatic explosives. Inorganica Chim Acta 515:120048 . https://doi.org/10.1016/j.ica.2020.120048

39. Saravanan S, Balachandran V (2014) Quantum chemical studies, natural bond orbital analysis and thermodynamic function of 2,5-dichlorophenylisocyanate. Spectrochim Acta - Part A Mol Biomol Spectrosc 120:351-364 . https://doi.org/10.1016/j.saa.2013.10.042

40. Politzer P, Abu-Awwad F (1998) A comparative analysis of Hartree-Fock and Kohn-Sham orbital energies. Theor Chem Acc 99:83-87 . https://doi.org/10.1007/s002140050307

41. Mulliken RS (1934) A new electroaffinity scale; Together with data on valence states and on valence ionization potentials and electron affinities. J Chem Phys 2:782-793 . https://doi.org/10.1063/1.1749394

42. Hoffmann R (1988) Solids and Surfaces: A Chemist's View of Bonding in Extended Structures. VCH Publishers, New York

43. Parr RG, Szentpály L V., Liu S (1999) Electrophilicity index. J Am Chem Soc 121:1922-1924 . https://doi.org/10.1021/ja983494x

44. Padmanabhan J, Parthasarathi R, Subramanian V, Chattaraj PK (2007) Electrophilicity-based charge transfer descriptor. J Phys Chem A 111:1358-1361 . https://doi.org/10.1021/jp0649549

45. Abbaz T, Bendjeddou A, Villemin D (2018) Structural Studies, NBO Analysis and Reactivity Descriptors of $\pi$-Extended Tetrathiafulvalene (exTTF) Connected to Thiophene Derivative. Arch Curr Res Int 14:1-13 . https://doi.org/10.9734/acri/2018/41529

\section{Table 3}

Table 3 not available with this version 
Figures
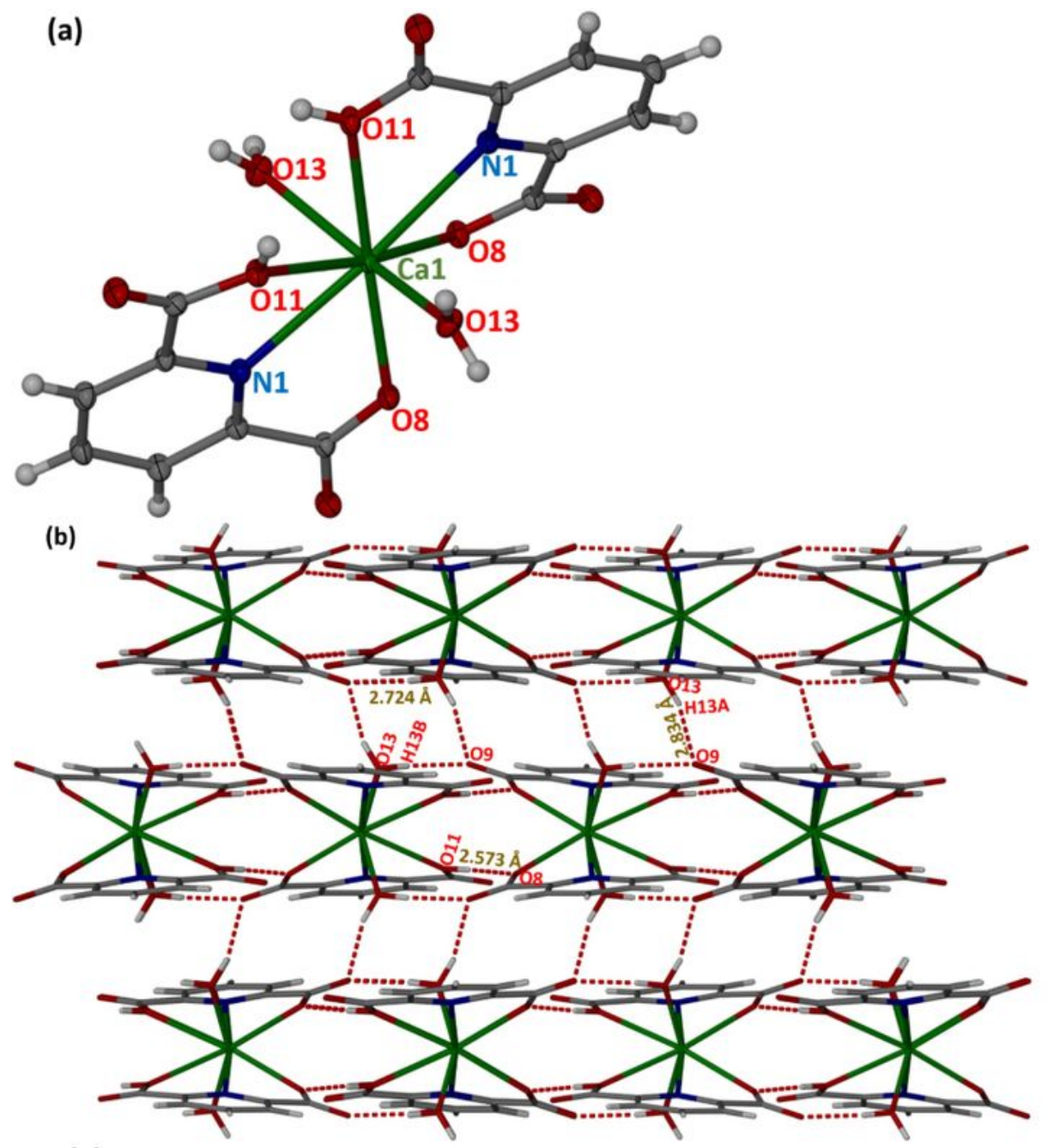

(c)

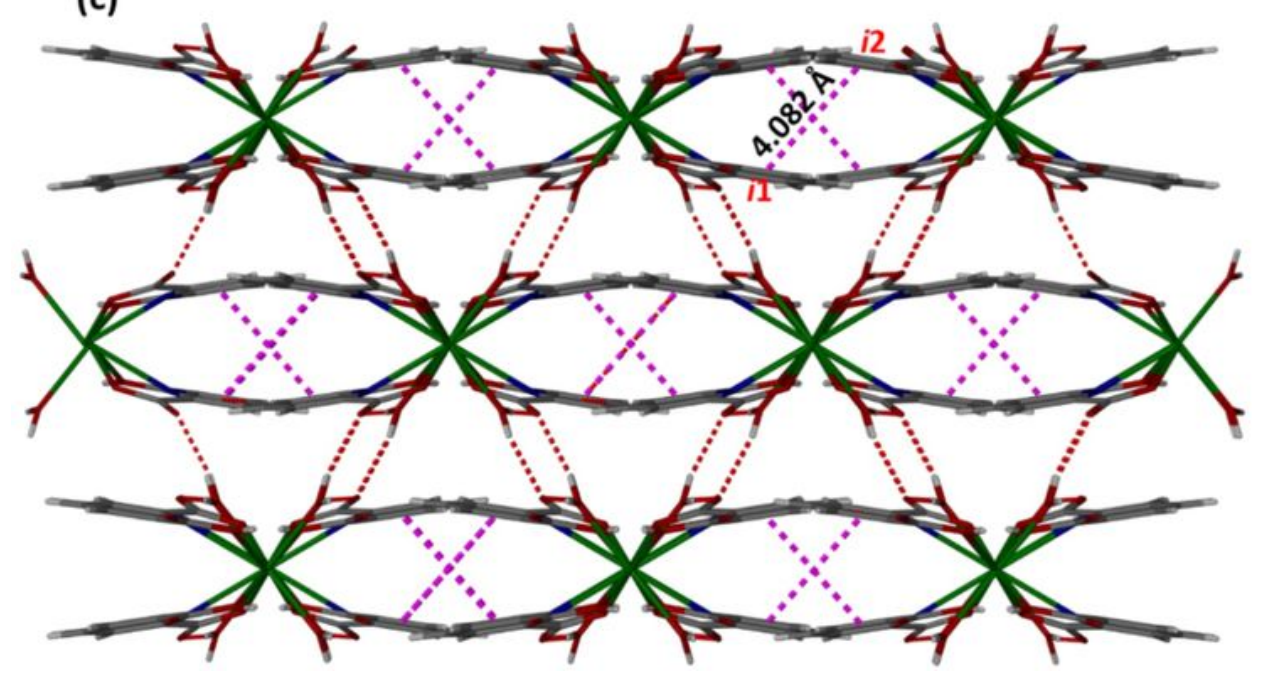

Figure 1

(a) ORTEP diagram of 1 with thermal ellipsoids drawn at 50\% probability level (b) packing arrangement showing $\mathrm{O}-\mathrm{H} \cdots \mathrm{O}$ hydrogen bonding intermolecular interactions in $\mathbf{1}$ (red) along a axis and (c) crystal packing of 1 showing the $\pi \cdots \pi$ interaction when viewed along the crystallographic $c$-axis (purple). 


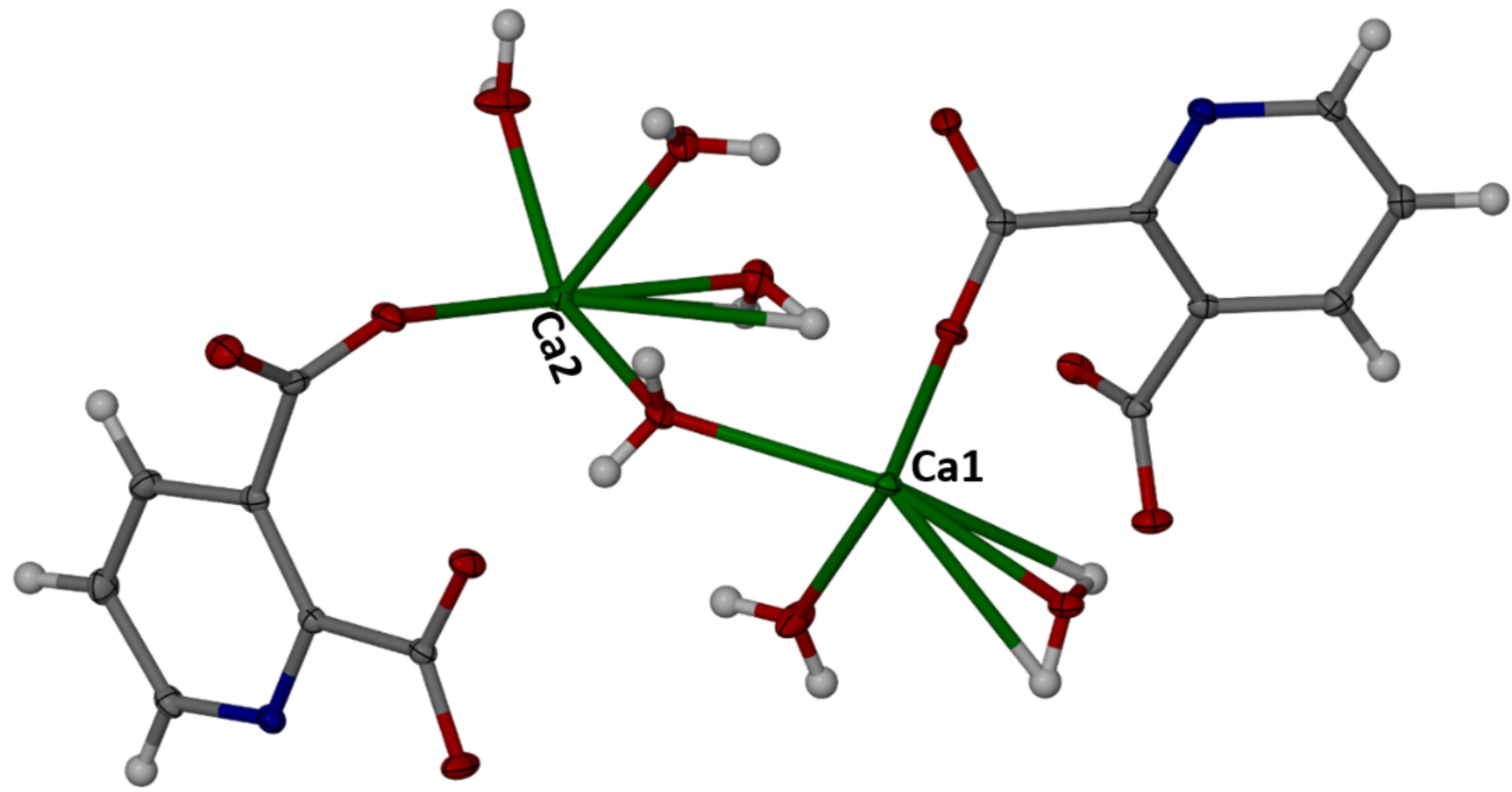

Figure 2

The asymmetric unit of compound 2 .

Figure 3

ORTEP diagram of $\mathbf{2}$ with thermal ellipsoids drawn at $50 \%$ probability level.

Figure 4

Crystal packing of 2 showing $\mathrm{O}-\mathrm{H} \cdots \mathrm{O}$ hydrogen bonding interactions when viewed along $c$-axis. 


\section{Figure 5}

Crystal packing of 2 showing $\mathrm{C}-\mathrm{H} \cdots \mathrm{O}$ hydrogen bonding interactions when viewed along $\mathrm{c}$-axis.

\section{Figure 6}

Crystal packing of 2 showing $\pi \cdots \pi$ interactions (purple) when viewed along $b$-axis.

\section{Figure 7}

Perspective showing 3D framework of 2 with $\mathrm{O}-\mathrm{H} \cdots \mathrm{O}$ (red), $\mathrm{C}-\mathrm{H} \cdots \mathrm{O}$ (blue) and $\pi \cdots \pi$ (purple) intermolecular interactions.

\section{Figure 8}

TGA curves of $\mathbf{1}$ and $\mathbf{2}$

\section{Figure 9}

Frontier molecular orbitals ((A) HOMO and (B) LUMO) for the optimized structure of 1 (Green, Blue, yellow and grey colours represent calcium, nitrogen, and carbon atoms respectively).

\section{Figure 10}

Frontier molecular orbitals ((A) HOMO and (B) LUMO) for the optimized structure of 2. (Green, Blue, yellow and grey colours represent calcium, nitrogen, and carbon atoms respectively). 


\section{Supplementary Files}

This is a list of supplementary files associated with this preprint. Click to download.

- Supplementarydatastructural.docx 